\title{
A criança e seus direitos na família e na sociedade: uma cartografia das leis e resoluções*
}

\author{
The rigths of the child in family and in society: \\ cartography of laws and resolutions \\ El niño y sus derechos en la familia y en la sociedad: \\ una cartografía de las leyes y de las resoluciones
}

\author{
Ilvana Lima Verde Gomes', Rosângela Caetano", Maria Salete Bessa Jorge' \\ 'Universidade Estadual do Ceará, Departamento de Enfermagem. Fortaleza, CE \\ "Universidade Estadual do Rio de Janeiro. Rio de Janeiro, RJ
}

Submissão: 03/10/2007

Aprovação: 13/12/2007

\section{RESUMO}

Esta pesquisa compreende uma revisão documental das leis, resoluções e outros documentos referentes ao direito das crianças e adolescentes existentes no Brasil e exterior, objetivando com isso uma compreensão e um conhecimento maior sobre a criança e seus direitos. Os documentos selecionados foram: a Declaração dos Direitos da Criança de 1959; a Constituição Federal do Brasil de 1988 ; a Carta da Criança Hospitalizada de 1988; o Estatuto da Criança e do Adolescente de 1990; e os Direitos da Criança e do Adolescente Hospitalizados (Resolução 41/95). Realizamos leitura flutuante de todos os documentos, citamos artigos relevantes ao tema, ressaltando algumas considerações. Concluímos Que já existem legislações Que protegem o direito da criança, porém é necessário garantir o usufruto desses direitos.

Descritores: Criança; Direitos da criança; Legislação.

\section{ABSTRACT}

This research is a documental review of laws, resolutions and others documents related to children and adolescents' rights existing in Brazil and overseas, aiming thus a comprehension and greater knowledge about the child and his rights. The documents chosen were: 1959's Pronouncement of Child Rights; 1988's Federal Constitution of Brazil; 1988's Letter of Hospitalized Child; 1990 's Statute of Child and Adolescent; and the Rights of Child and Adolescent hospitalized (Resolution 41/95). We did floating reading of all documents, mentioning relevant articles to theme, highlighting some considerations. We conclude that already exist legislations that protect the right of child, though it is necessary to ensure the use of these rights.

Descriptors: Child; Child rights; Legislation.

\section{RESUMEN}

Esta investigación comprende una revisión documental de las leyes, resoluciones y otros documentos referentes al derecho de los niños y adolescentes en Brasil y en el exterior y tiene como objetivo una comprensión y un conocimiento mayor sobre el niño y sus derechos. Los documentos seleccionados han sido: la Declaración de los Derechos del Niño de 1959; la Constitución Federal de Brasil de 1988; la Carta del Niño Hospitalizado, de 1988; el Estatuto del Niño y del Adolescente de 1990; y los Derechos del Niño y del Adolescente Hospitalizados (Resolución 41/95). Hemos realizado lectura fluctuante de todos los documentos, citamos artículos relevantes al tema y resaltamos algunas consideraciones. Hemos concluido que ya existen legislaciones que protegen el derecho de los niños, pero es necesario garantizar el usufructo de esos derechos.

Descriptores: Niño; Derechos del niño; Legislación. 


\section{INTRODUÇÃO}

Em virtude da dependência e da fragilidade da criança nos primeiros anos de vida, durante muitos séculos ela foi ignorada. A idéia de infância estava ligada à idéia de dependência; só se saía da infância ao se afastar de graus mais baixos de dependência. Na sociedade medieval, a consciência da particularidade infantil, Que distingue essencialmente a criança do adulto, não existia. Por isso, Quando a criança podia viver sem as solicitudes constantes da mãe ou de sua ama, ela ingressava na sociedade dos adultos e não mais se distinguia deles ${ }^{(1)}$.

No Brasil colonial, o filho ocupava uma posição secundária na família; uma imagem despida de atrativos tinha direito a uma atenção genérica, não-personalizada. A família colonial ignorava a criança ou a subestimava, privando-a da afeição indispensável ao seu desenvolvimento físico e emocional. A criança tinha uma vida paralela à economia doméstica, era um acessório supérfluo; ao paiproprietário, interessava o filho adulto ${ }^{(2)}$.

Na opinião de $\operatorname{Costa}^{(2)}$, a excessiva importância dada ao pai, ao patrimônio e à religião reduziu, expressivamente, o espaço físico e sentimental da criança. Tratada como um "adulto incompetente", sua existência não possuía, por assim dizer, nenhum conteúdo positivo. Ela era percebida negativamente, por oposição ao adulto.

Somente a partir do século XX a criança começou a ter lugar nas leis e códigos no mundo e, por extensão, no Brasil. Barroso ${ }^{(3)}$ descreve este século como um século de descobertas, grandes invenções tecnológicas, devastadoras guerras civis e mundiais, mas fundamentalmente o século da descoberta da criança como um sujeito de direitos.

A importância de olhar a criança como um ser Que existe e, diante da sua fragilidade e dependência, procurar meios para protegê-la, levou vários seguimentos da sociedade e instituições a lutarem pela elaborações de leis em sua defesa.

Por sermos profissionais de saúde e de atuação na área pediátrica, tanto na assistência como na docência, objetivamos realizar um levantamento histórico sobre documentos brasileiros e estrangeiros Que abordem os direitos da criança, sadia e/ou hospitalizada, possibilitando, assim, uma compreensão e um conhecimento maior sobre essa temática.

\section{METODOLOGIA}

Trata-se de um estudo de revisão documental das Leis, Resoluções, Estatutos, entre outros documentos existentes no Brasil e no exterior Que abordem os direitos da criança sadia e/ou hospitalizada.

Entre os documentos encontrados elegemos os Que são mais representativos e relevantes no nosso país e no mundo, sendo citados em vários artigos pertinentes à nossa temática.

Os documentos selecionados foram: a Declaração dos Direitos da Criança de $1959^{(4)}$, capturado na internet pelo site da UNICEF; a Constituição Federal do Brasil de $1988^{(5)}$; a Carta da Criança Hospitalizada de $1988^{(6)}$, capturada na internet pelo site http:// www.iacriança.pt; o Estatuto da Criança e do Adolescente de 1990(7); e os Direitos da Criança e do Adolescente Hospitalizados (Resolução 41/95) ${ }^{(8)}$.

Para organização do material coletado efetuamos leitura flutuante e, depois, os ordenamos por ordem cronológica de promulgação e/ ou publicação.

Cada documento selecionado foi examinado, citado na íntegra ou resumidamente, ou só os artigos relevantes ao tema, e ressaltado algumas considerações.

\section{RESULTADOS}

Em 1923, uma organização não-governamental, a International Union for Children Welfare, promulgou as primeiras leis de proteção à infância. Esse documento foi incorporado na primeira Declaração dos Direitos da Criança de 1924, em Genebra, pela Liga das Nações ${ }^{(3)}$.

Após a Segunda Grande Guerra Mundial, para evitar os massacres e atrocidades ocorridas durante este conflito contra as crianças, homens e mulheres, volta-se a discutir sobre os direitos fundamentais da pessoa humana. Em 10 de dezembro de 1948, na cidade de Paris, foi elaborada e aprovada, pela Assembléia das Nações Unidas (ONU), a Declaração Universal dos Direitos do Homem, inspirada em antigas declarações, universalizando princípios e adaptando-os aos acontecimentos contemporâneos ${ }^{(9,3)}$.

De acordo com Bobbio $^{(10)}$, o primeiro anúncio do reconhecimento dos direitos do cidadão de cada Estado e do mundo foi a Declaração Universal dos Direitos do Homem. Segundo o autor, "somente depois da Declaração Universal é que podemos ter a certeza histórica de que a humanidade - e toda a humanidade partilha alguns valores comuns".

Apesar de a Declaração abranger todos os seres humanos, houve necessidade de se criar um outro documento Que falasse especificamente da criança. Em 1959, no dia 20 de novembro, foi aprovada por unanimidade e proclamada na Assembléia Geral das Nações Unidas, a Declaração dos Direitos da Criança. Muitos dos direitos e liberdades contidos neste documento fazem parte da Declaração Universal dos Direitos Humanos ${ }^{(4)}$.

É um momento de muita importância para a infância, pois torna a criança um sujeito de direitos, preservando sua dignidade como pessoa humana.

Esta Declaração consta de dez direitos, cada um baseado em um princípio, resumidamente exposto a seguir: Direito à igualdade, sem distinção de raça, religião ou nacionalidade; Direito à especial proteção para o seu desenvolvimento físico, mental e social; Direito a um nome e uma nacionalidade; Direito à alimentação, moradia e assistência médica adequada para a criança e sua mãe; Direito à educação e a cuidados especiais para a criança física ou mentalmente deficiente; direito ao amor e à compreensão dos pais e da sociedade; Direito à educação gratuita e ao lazer infantil; Direito a ser socorrido em primeiro lugar, em caso de catástrofes; Direito a ser protegida contra o abandono e a exploração no trabalho; e Direito a crescer, dentro de um espírito de solidariedade, compreensão, amizade e justiça entre os povos ${ }^{(4,3)}$.

Além disso, em 1945 foi criado o United Nations Children's Fund - UNICEF, órgão internacional Que vem, ao longo dos anos, ampliando seu campo de atuação, como uma das principais instituições na luta pela defesa e garantia dos direitos da criança e do adolescente ${ }^{(3)}$.

No Brasil, a história da criança e sua repressão começaram a ter notoriedade em 1978, instituído como o Ano Internacional da 
Criança. A partir desse momento, diversas associações se articularam em defesa dos direitos da criança, influenciando o Estatuto da Criança e do Adolescente de $1990^{(11)}$.

Outro documento relevante, a Constituição Federal de $1988^{(5)}$, conhecida como a Constituição cidadã, também defende os direitos da criança. Segundo Dallari(12) esta Constituição "nasceu intrinsecamente ligada à idéia de que os homens têm direitos inalienáveis decorrentes da sua condição humana”. Ela, além de garantir a assistência integral à saúde, a licença gestante e a licença paternidade, garante também o direito da criança de zero a seis anos de idade a freeüentar a pré-escola (ou educação infantil, como se chama atualmente). E, no seu Art. 227, afirma:

É dever da família, da sociedade e do Estado assegurar à criança e ao adolescente, com absoluta prioridade, o direito à vida, à saúde, à alimentação, à educação, ao lazer, à profissionalização, à cultura, à dignidade, ao respeito, à liberdade e à convivência familiar $\mathrm{e}$ comunitária, além de colocá-los a salvo de toda forma de negligência, discriminação, exploração, violência, crueldade e opressão.

Depois da Constituição de 1988, foi publicado o Estatuto da Criança e do Adolescente (ECA), de 1990, Que é um marco nos direitos da criança e do adolescente ${ }^{(7)}$. Marco porQue veio assegurar à criança e ao adolescente todos os direitos fundamentais inerentes à pessoa humana.

$\mathrm{O}$ Art. $3^{\circ}$ do ECA menciona Que:

A criança e o adolescente gozam de todos os direitos fundamentais inerentes à pessoa humana, sem prejuízo da proteção integral de Que trata esta Lei, assegurando-se-lhes, por lei ou por outros meios, todas as oportunidades e facilidades, a fim de lhes facultar o desenvolvimento físico, mental, moral, espiritual e social, em condições de liberdade e de dignidade.

A partir desse Estatuto, a criança é vista, pelo menos teoricamente, como um ser humano completo, com

(...) direito à liberdade, ao respeito à dignidade como pessoas humanas em processo de desenvolvimento e como sujeitos de direitos civis, humanos e sociais garantidos na Constituição e nas leis. (Art. 15 do ECA).

Como afirma Marques ${ }^{(13)}$, a despeito das inúmeras falhas, o ECA é "sem dúvida, um marco na longa caminhada em direção a superação da injusta situação social ainda vivida por muitas crianças no Brasil".

Com o ECA, vários órgãos se engajaram em uma luta com vistas à sua implantação. Entre estes, sobressaem o Conselho Nacional dos Direitos da Criança e do Adolescente (CONANDA), o Programa Nacional de Atenção Integral à Criança e ao Adolescente (PRONAICA), o Conselho da Comunidade Solidária e os Conselhos Tutelares ${ }^{(3)}$.

A Constituição Federal e o ECA abrangem os direitos da criança como um todo, embora alguns artigos sejam mais específicos na área da saúde, principalmente o Art. 12 do Estatuto, Que resguarda o direito do acompanhante euando a criança se interna, recomendando Que "os estabelecimentos de atenção à saúde deverão proporcionar condições para a permanência em tempo integral de um dos pais ou responsável”. Houve, porém, necessidade de proteger o direito da criança dentro do hospital. Em conseQüência, existem - e não apenas no Brasil — documentos específicos sobre o assunto. Citaremos dois deles: A Carta da Criança Hospitalizada, Que é européia, e a Resolução 41/95, Que é brasileira.
Em 1988, várias associações européias elaboraram a "Carta da Criança Hospitalizada", composta de oito itens que de forma sucinta estão dispostos a seguir:

A criança só deve ser hospitalizada Quando os cuidados necessários à sua doença não possam ser prestados em casa, em consulta ou em hospital de dia; A criança hospitalizada tem direito a ter os pais ou seus substitutos, junto dela, dia e noite, sendo facultadas, aos pais, facilidades materiais sem Que isso implique Qualquer encargo financeiro ou perda de salário. Os mesmos devem ser informados sobre as regras e as rotinas do serviço para Que participem ativamente nos cuidados ao seu filho; As crianças e seus pais têm o direito de receber informação adequada sobre a doença e os tratamentos, a fim de poderem participar nas decisões Que lhes dizem respeito; Deve evitar-se QualQuer exame ou tratamento Que não seja indispensável. As agressões físicas ou emocionais e a dor devem ser reduzidas ao mínimo; As crianças não devem ser admitidas em serviços de adulto, devem ficar reunidas por grupos etários para se beneficiarem de jogos, recreios e atividades educativas adaptadas à idade. As visitam devem ser aceitas sem limites de idade; O hospital deve oferecer às crianças um ambiente que corresponda às suas necessidades físicas, afetivas e educativas, Quer no aspecto do equipamento, Quer no do pessoal e da segurança; A equipe de saúde deve ter a formação adeeuada para responder às necessidades psicológicas e emocionais das crianças e da família ${ }^{(6)}$.

lá no Brasil, a Sociedade Brasileira de Pediatria elaborou os Direitos da Criança e do Adolescente Hospitalizados, Que foi apresentado e aprovado por unanimidade na $27^{\mathrm{a}}$. Assembléia Ordinária do CONANDA, transformando-se na Resolução de número 41 de 17 de outubro de $1995^{(8)}$. Esta Resolução consta de vinte itens, todos direcionados a proteger a criança e o adolescente hospitalizado, tanto de ser atendido no sistema de saúde como de ser tratado dignamente.

Sumariamente, a Resolução 41/95 delibera sobre os seguintes direitos: À proteção à vida e à saúde, com absoluta prioridade e sem Qualeuer forma de discriminação; Ser hospitalizado Quando for necessário ao seu tratamento, sem distinção de classe social, condição econômica, raça ou crença religiosa; Não ser ou permanecer hospitalizado desnecessariamente por QualQuer razão alheia ao melhor tratamento de sua enfermidade; Ser acompanhado por sua mãe, pai ou responsável, durante todo o período de sua hospitalização, bem como receber visitas; Não ser separado de sua mãe ao nascer; Receber aleitamento materno sem restrições; Não sentir dor, Quando existem meios para evitá-la; Ter conhecimento adequado de sua enfermidade, dos cuidados terapêuticos e diagnósticos a serem utilizados, do prognóstico, respeitando sua fase cognitiva, receber amparo psicológico, Quando se fizer necessário.

Além desses aspectos, a criança e o adolescente têm o direito de desfrutar de alguma forma de recreação, programas de educação para a saúde, acompanhamento do currículo escolar, durante sua permanência hospitalar; Os pais ou responsáveis participem ativamente do seu diagnóstico, tratamento e prognóstico, recebendo informações sobre os procedimentos a Que será submetido; Apoio espiritual e religioso conforme prática de sua família; Não ser objeto de ensaio clínico, provas diagnósticas e terapêuticas, sem o consentimento informado de seus pais ou responsáveis e o seu 
próprio, Quando tiver discernimento para tal; Receber todos os recursos terapêuticos disponíveis para sua cura, reabilitação e ou prevenção secundária e terciária;

Também tem o direito de receber proteção contra QualQuer forma de discriminação, negligência ou maus tratos; Respeito a sua integridade física, psíquica e moral; Prevenção de sua imagem, identidade, autonomia de valores, dos espaços e objetos pessoais; Não ser utilizado pelos meios de comunicação, sem a expressa vontade de seus pais ou responsáveis, ou a sua própria vontade, resguardando-se a ética; Confidência dos seus dados clínicos, bem como direito a tomar conhecimento dos mesmos, arQuivados na instituição; Ter seus direitos constitucionais e os contidos no Estatuto da Criança e Adolescente respeitados pelos hospitais integralmente; e finalmente, a ter uma morte digna, junto a seus familiares, Quando esgotados todos os recursos terapêuticos disponíveis.

Todos esses direitos apreendidos nos documentos a Carta da Criança Hospitalizada e a Resolução 41/95 são importantes para a o bom cuidado da criança hospitalizada, porém destacamos aspectos Que parecem ser violados com freqüência, ou pouco respeitados pelos profissionais de saúde e/ou Instituições de saúde.

É primordial Que as instituições de internação observem o Que esta disposto na Resolução 41/95, conforme a Qual as crianças não devem ser ou permanecerem hospitalizados desnecessariamente por QualQuer razão alheia ao melhor tratamento de sua enfermidade. Ocorre, em muitos internamentos, demoras na realização de exames e/ou procedimentos necessários para Que a alta da criança possa ocorrer, estendendo os dias de hospitalização, expondo-a aos riscos inerentes ao ambiente hospitalar e afastando-a do convívio com os demais familiares e seu ambiente domestico.

Cremos ser necessário também ressaltar Que, embora não presente na Resolução citada, existe na Carta da Criança Hospitalizada a recomendação de Que a admissão de uma criança no hospital só deva ocorrer Quando os cuidados indispensáveis à sua doença não podem ser prestados em casa, em consulta externa ou em hospital-dia.

Quanto ao direito ao acompanhante, existe tanto no ECA, na Carta da Criança Hospitalizada como na Resolução 4l/95. Esse direito é atendido pelas Instituições hospitalares, porém, até hoje, muitos hospitais não reservam uma acomodação e alimentação digna para o acompanhante. A Carta da Criança Hospitalizada delibera Que "os pais devem ser encorajados a ficar junto do seu filho e devendo ser-lhes facultadas facilidades materiais sem Que isso implique QualQuer encargo financeiro ou perda de salário" (item $3 ; \mathrm{p}: 8$ ) .

Outro direito abordado na Resolução 41/95 ressalta Que a criança tem o direito "a ter conhecimento adequado de sua enfermidade, dos cuidados terapêuticos e diagnósticos (...)”, porém a relação e a comunicação do profissional de saúde com a criança se restringem ao afetivo, principalmente para Que a criança colabore nos procedimentos ou exames. Essa infantilização nega-lhe as conQuistas alcançadas pelo seu estágio de desenvolvimento. Há uma desapropriação da criança em relação ao conhecimento do seu corpo e lhe é imposta uma disciplina institucional ${ }^{(14,15,16)}$.

Segundo delibera a Resolução 41/95, os pais ou responsáveis têm o direito de "participarem ativamente do diagnóstico, tratamento e prognóstico da criança, recebendo informações sobre os procedimentos a Que será submetida”. De modo similar, mas inclusive ampliando o escopo de Quem tem direito à informação, também conforme consta na a Carta da Criança Hospitalizada, "crianças e seus pais têm o direito de receber uma informação sobre a doença e os tratamentos, adequada à idade e à compreensão (grifo nosso), a fim de poderem participar nas decisões que lhes dizem respeito".

Para a boa observância desse aspecto, há necessidade de que aconteça a comunicação em todas as áreas. A comunicação é um instrumento essencial particularmente no cuidado à saúde. Ainda hoje, por todo o mundo, os doentes não recebem informações suficientes e apropriadas sobre seu estado de saúde e sobre as possibilidades e conseqüências de tratamento. Desse modo, prevalece um relacionamento paternalista, no Qual o paciente é dependente do julgamento e das idéias do médico ${ }^{(17)}$.

O cuidado, como uma ação integral para o ser humano e do ser humano Que vive na busca contínua do cuidado, diante da fragilidade social existente no mundo capitalista, segundo Luz ${ }^{(18)}$, não é um procedimento técnico simplificado, mas o tratar, o respeitar, o acolher, o atender o ser humano em seu sofrimento ${ }^{(19,18)}$.

No cuidado integral, como proposto por Pinheiro e Guizardi, deve haver o dialogismo como um elemento constitutivo; sua prática resulta do embate de muitas vozes sociais e, Quando eficazes, pode produzir efeitos de polifonia - Quando essas vozes se deixam escutar. Mas Quando o diálogo é mascarado e só uma voz apenas se faz ouvir, acontece à monofonia ${ }^{(19)}$. .

Observamos que já existem leis para assegurar os direitos da criança, tanto a sadia como a Que esta hospitalizada. Porém, apesar de tantas leis, de tanto avanço nas coneuistas dos direitos humanos, no referente à criança, ainda existe profundo abismo entre o Que está escrito e o que acontece na realidade. Como mostra o cotidiano, a violação desses direitos é um fato diário no Brasil, e somos testemunhas do Quanto mulheres e crianças continuam sendo vítimas das piores violências e injustiças ${ }^{(3,13)}$.

Bobbio $^{(10)}$ corrobora estas afirmações Quando diz Que o problema mais urgente a ser enfrentado não é o de fundamentar os direitos do homem, mas de garanti-los para não serem violados. "A liberdade e a igualdade dos homens não são um dado de fato, mas um ideal a perseguir; não são uma existência, mas um valor; não são um ser, mas um dever ser".

Como vimos nas citações de vários autores, o Que precisamos, no momento é proteger os direitos expostos nas leis e outros documentos, para Que eles sejam usufruídos pelas crianças. É importante e urgente a necessidade de garantir o gozo pleno desses direitos expostos anteriormente, para Que a criança e o adolescente, como cidadão Que são, sejam respeitados na sua dignidade. Nisto consiste a relevância desse trabalho, em divulgar as leis e/resoluções existentes sobre os direitos da criança e do adolescente.

\section{CONSIDERAÇÕES FINAIS}

A busca de apreender os diversos documentos que tratam dos direitos das crianças e dos adolescentes, a fim de realizar essa pesQuisa, nos levou a refletir sobre esses direitos e suas aplicações. Percebemos, na nossa lida diária em hospitais, Que muitas vezes os próprios profissionais de saúde cerceiam esses direitos. Talvez, por falta de conhecimento dos documentos citados anteriormente. Entendemos Que, como profissionais Que somos, devemos 
corroborar para Que esses direitos sejam desfrutados integralmente por essas crianças e seus pares. Por isso, sugerimos que as instituições de ensino e de saúde promovam discussões, ciclos de debates sobre o assunto, bem como os coloquem em lugares estratégicos, para Que todos os cidadãos possam tomar conhecimento de tais documentos.

\section{REFERÊNCIAS}

I. Ariès P. História social da criança e da família. $2^{\mathrm{a}}$ ed. Rio de Janeiro (RJ): LTC; 1981.

2. Costa JF. Ordem médica e norma familiar. $4^{\mathrm{a}}$ ed. Rio de Janeiro (RI): Graal; 1999.

3. Barroso LMS. As idéias das crianças e adolescentes sobre seus direitos: um estudo evolutivo à luz da teoria piagetiana [dissertação]. Campinas (SP): Faculdade de Educação, Universidade Estadual de Campinas; 2000.

4. UNICEF. Declaração dos direitos da criança. [citado em: 0 I jan 2004]. Disponível em: URL: http://www.unicef.org/brazil

5. Brasil. Constituição da República Federativa do Brasil de 1988. São Paulo (SP): Ed. Revista dos Tribunais; 1989.

6. Instituto de Apoio à Criança. Carta da criança hospitalizada. [citado em 10 out 2000]. Disponível em: URL: http:// www.iacriança.pt

7. Brasil. Lei n. 8069, de 13 de julho. Estatuto da Criança e do Adolescente (ECA). Fortaleza (CE): Conselho Estadual dos Direitos da Criança e do Adolescente do Ceará; 1991.

8. Brasil. Conselho Nacional de Defesa dos Direitos da Criança e Adolescente (BR). Resolução no 41, 13 de outubro de 1995. Dispõe sobre os direitos da criança hospitalizada. Diário Oficial da Republica Federativa do Brasil 199517 out; Seção I: 163.

9. Gomes ILV, Fraga MNO. Direitos do cidadão hospitalizado: teoria e práxis. Fortaleza (CE): Ban Gráfica; 2001.

10. Bobbio N. A era dos direitos. Rio de Janeiro (RI): Campus; 1992.

I I. Passetti E. O menor no Brasil republicano. In: Priori MD, organizador. Historia da criança no Brasil. $4^{\mathrm{a}}$ ed. São Paulo
(SP): Contexto; 1996. p. 146-75.

12. Dallari SG. Os estados brasileiros e o direito à saúde. São Paulo (SP): Hucitec; 1995.

13. Marques MB. Discursos médicos sobre seres frágeis. Rio de Janeiro (RI): Fiocruz; 2000.

14. Perosa GB, Gabarra LM. Explicações de crianças internadas sobre a causa das doenças: implicações para a comunicação profissional de saúde-paciente. Interface - Comunicação, Saúde, Educação 2004; 8(14): 135-47.

15. Oliveira $H$. Ouvindo a criança sobre a enfermidade e a hospitalização. In: Ceccim RB, Carvalho PRA, organizadores. Criança hospitalizada: atenção integral como escuta à vida. Porto Alegre (RS): Editora da Universidade/UFRGS; 1997. p. 42-55.

16. Capobianco CSM. O corpo em off: a doença e as práticas psi na pediatria hospitalar. São Paulo (SP): Estação Liberdade, 2003.

17. Caprara A, Franco ALS. A relação paciente-médico: para uma humanização da prática médica. Cad Saúde Pública 1999; 15(3): 647-54.

18. Luz MT. Fragilidade social e busca de cuidado na sociedade civil de hoje. In: Pinheiro R, Mattos RA, organizadores. Cuidado: as fronteiras da integralidade. Rio de laneiro (RI): ABRASCO; 2004. p. 9-20.

19. Pinheiro R, Guizardi FL. Cuidado e integralidade: por uma genealogia de saberes e práticas no cotidiano. In: Pinheiro R, Mattos RA, organizadores. Cuidado: as fronteiras da integralidade. Rio de Janeiro (RI): ABRASCO; 2004. p. 2 I-36. 